\title{
On Harmonic Univalent Functions Involving (p,q)-Poisson Distribution Series
}

\author{
Sibel Yalçın ${ }^{1}$, Hasan Bayram ${ }^{2 *}$ \\ ${ }^{1}$ Mathematics/Faculty of Arts and Sciences, Bursa Uludag University, Turkey ORCID ID 0000-0002-0243-8263 syalcin@uludag.edu.tr \\ 2* Mathematics/Faculty of Arts and Sciences, Bursa Uludag University, Turkey ORCID ID 0000-0001-8106-6834hbayram@uludag.edu.tr
}

(1st International Conference on Applied Engineering and Natural Sciences ICAENS 2021, November 1-3, 2021)

(DOI: 10.31590/ejosat.1012504)

ATIF/REFERENCE: Yalçın, S. \& Bayram H. (2021). On Harmonic Univalent Functions Involving (p,q)-Poisson Distribution Series. European Journal of Science and Technology, (28), 1048-1051.

\begin{abstract}
Harmonic functions are a classic title in the class of geometric functions. Many researchers have studied these function classes from past to present, and since it has a wide range of applications, it is still a popular class. In this study, we will examine harmonic univalent functions, a subclass of harmonic functions. In this study, a subclass of harmonic univalent functions will be examined. Let $H$ denote the class of continuous complex-valued harmonic functions which are harmonic in the open unit disk $U=\{z \in \mathbb{C}:|z|<1\}$ and let $A$ be the subclass of $H$ consisting of functions which are analytic in $U$. A function harmonic in $U$ may be written as $f=h+\bar{g}$, where $h$ and $g$ are analytic in $U$. We call $h$ the analytic part and $g$ co-analytic part of $f$. A necessary and sufficient condition for $f$ to be locally univalent and sense-preserving in $U$ is that $\left|h^{\prime}(z)\right|>\left|g^{\prime}(z)\right|$ (see [3]). Throughout this paper, we will use introductory notations and delineations of the (p, q)- calculus.

The aim of the present paper is to find connections between $(\mathrm{p}, \mathrm{q})$-starlike harmonic univalent functions involving (p, $\mathrm{q})$-Poisson distribution series.
\end{abstract}

Keywords: Complex harmonic functions, univalent functions, (p,q)-calculus, (p,q)-starlike functions.

\section{(p,q)-Poisson Dağılım Serisi İçeren Harmonik Yalınkat Fonksiyonlar Üzerine}

Öz

Harmonik fonksiyonlar, geometrik fonksiyonlar teorisinde klasik bir başlıktır. Geçmişten günümüze bir çok araştırmacı Harmonik fonksiyon sınıflarını ve bu fonksiyonların geniş uygulama alanlarını çalışmışlardır. Bu konu günümüzde de hala popülerliğini korumaktadır. Biz bu çalışmada harmonic yalınkat fonksiyonların bir alt sınıfını çalışacağız. Bu makalede harmonic fonksiyonların bir alt sınıfını tanımlayacağız. $H, U=\{z \in \mathbb{C}:|z|<1\}$ açık birim disk olmak üzere; $U$ diskinde kompleks değerli sürekli fonksiyonların oluşturduğu sınıfı temsil etsin. $A$ ise birim diskte analitik fonksiyonların oluşturduğu ve $H$ sınıfının alt sınıfı olsun. Bir fonksiyon $U$ açık birim diskinde harmonik ise $h$ ve $g$ analitik fonksiyon olmak üzere $f=h+\bar{g}$ tipinde yazılabilir. Burada $h$ fonksiyonu $f$ fonksiyonunun analitik kısmı $g$ ise co-analitik kısmı olarak tanımlanır. $f$ fonksiyonunun $U$ birim diskinde yerel yalınkat ve yön koruyan olması için gerek ve yeter şart $\left|h^{\prime}(z)\right|>\left|g^{\prime}(z)\right|$ olmasıdır (bkz. [3]). Bu makale boyunca, (p, q)- hesabının giriş notasyonlarını ve tasvirlerini kullanacağız. Bu makalenin amacı, (p,q)-Poisson dağılım serilerini içeren (p,q)-yıldız benzeri harmonik tek değerli fonksiyonlar arasındaki bağlantıları bulmaktır.

Anahtar Kelimeler: Kompleks harmonik fonksiyonlar, univalent fonksiyonlar, (p,q)-hesabı, (p,q)-yıldızıl fonksiyonlar.

\footnotetext{
* Corresponding Author: hbayram@uludag.edu.tr
} 


\section{Introduction}

From the summary text, without loss of generality, we may write

$$
h(z)=z+\sum_{k=2}^{\infty} a_{k} z^{k} \text { and } g(z)=\sum_{k=2}^{\infty} b_{k} z^{k} .
$$

Let $S H$ denote the class of functions $f=h+\bar{g}$ which are harmonic, univalent and sense-preserving in $U$ for which $h(0)=$ $h^{\prime}(0)-1=0=g(0)$. One shows easily that the sensepreserving property implies that $\left|b_{1}\right|<1$. The subclass $S H^{0}$ of $\mathrm{SH}$ consist of all functions in $\mathrm{SH}$ which have the additional property $b_{1}=0$. Clunie and Sheil-Small [3] investigated the class $S H$ as well as its geometric subclasses and obtained some coefficient bounds.

Indeed Conception of q-calculus is the post-quantum calculus, denoted (p, q)-calculus. The (p, q)- integer was introduced in order to give a conception or to unify several forms of q-oscillator algebras, well known in the earlier physics literature related to the representation proposition of single parameter amount algebras [2]. Throughout this paper, we will use introductory notations and delineations of the $(p, q)$ - calculus as follows: Let $p>0, q>0$. For any non-negative integer $k$, the $(\mathrm{p}, \mathrm{q})$-integer number $k$, denoted by $[k]_{p, q}$ is

$$
[k]_{p, q}=\frac{p^{k}-q^{k}}{p-q}, \quad(k=1,2,3, \ldots), \quad[0]_{p, q}=0 .
$$

The binary-introductory number is a natural conception of the q- number, that is,

$$
[k]_{q}=\frac{1-q^{k}}{1-q}, \quad(k=1,2,3, \ldots), \quad q \neq 1 .
$$

Likewise, the (p, q)-differential operator of a function $f$, analytic in $U$ is defined by

$$
D_{p, q} f(z)=\frac{f(p z)-f(q z)}{(p-q) z}, \quad p \neq q, \quad z \in \mathbb{U} .
$$

One can easily show that $D_{p, q} f(z) \rightarrow f(z)$ as $p \rightarrow 1^{-}$and $q \rightarrow 1^{-}$. It is clear that q-integer and (p, q)-integers differs, that is, we cannot obtain (p, q)-integers just by replacing $q$ by $q / p$ in the definition of q-integers. Also, clearly $\lim _{q \rightarrow 1^{-}} \quad \lim _{p \rightarrow 1^{-}}[k]_{p, q}=$ $k$. For details on q-calculus and (p,q)-calculus, one can refer to $[2,5,10]$.

In 1990, Ismail et. al. [4] used q-calculus, in the theory of analytic univalent functions by defining a class of complex valued functions that are analytic on the open unit disk $\mathbb{U}$ with the normalizations $f(0)=0, f^{\prime}(0)=1$, and $|f(q z)| \leq|f(z)|$ on $\mathbb{U}$ for every $q, q \in(0,1)$. Motivated by these authors, several inquiries used the proposition of analytic univalent functions and q- calculus; for illustration see [8] and [9]. The q- difference operator of analytic functions $\mathrm{h}$ and $\mathrm{g}$ given by (1) are by description, given as follows [10].

$$
\begin{aligned}
& D_{p, q} h(z)=\left\{\begin{array}{l}
\frac{h(p z)-h(q z)}{(p-q) z} ; z \neq 0 \\
h^{\prime}(0)
\end{array} \text { and } D_{p, q} g(z)\right. \\
& =\left\{\begin{array}{l}
\frac{g(p z)-g(q z)}{(p-q) z} ; z \neq 0 \\
g^{\prime}(0) \quad ; z=0
\end{array}\right.
\end{aligned}
$$

Thus, for the function $h$ and $g$ of the form (1), we have

$$
\begin{aligned}
D_{p, q} h(z) & =1+\sum_{k=2}^{\infty}[k]_{p, q} a_{k} z^{k-1} \text { and } D_{p, q} g(z) \\
& =\sum_{k=1}^{\infty}[k]_{p, q} b_{k} z^{k-1} .
\end{aligned}
$$

A harmonic function $f=h+\bar{g}$ defined by (1) is said to be q-harmonic, locally univalent and sense-preserving in $U$ denoted by $S H_{p, q}$, if and only if the second dilatation $w_{p, q}$ satisfies the condition

$$
\left|w_{p, q}(z)\right|=\left|\frac{D_{p, q} g(z)}{D_{p, q} h(z)}\right|<1
$$

where $0<p, q<1$ and $z \in U$. Note that as $p \rightarrow 1^{-}$and $q \rightarrow 1^{-}, S H_{p, q}$ reduces to the family $S H$ (see [3]).

Denote by $S H_{p, q}^{*}(\alpha)$ the subclass of $S H_{p, q}$ consisting of functions $f$ of the form (1) that satisfy the condition

$$
\operatorname{Re}\left[\frac{z D_{p, q} h(z)-\overline{z D_{p, q} g(z)}}{h(z)+\overline{g(z)}}\right]>\alpha
$$

where is $0<p, q<1, z \in U, 0 \leq \alpha<1, D_{p, q} h(z)$ and $D_{p, q} g(z)$ are defined by (2) (see for details [1]). We will call (p,q)-starlike harmonic functions of order $\alpha$.

Define $T S H_{p, q}^{*}(\alpha)=S H_{p, q}^{*}(\alpha) \cap T$ where $T$ consisting of the functions $f=h+\bar{g}$ in $S H_{p, q}$ so that $h(z)$ and $g(z)$ are of the form

$$
\begin{aligned}
& h(z)=z-\sum_{k=2}^{\infty}\left|a_{k}\right| z^{k}, g(z)=\sum_{k=1}^{\infty}\left|b_{k}\right| z^{k},\left|b_{1}\right| \\
& <1 .
\end{aligned}
$$

By suitably specializing the parameters, the class $S H_{p, q}^{*}(\alpha)$ reduce to the various subclasses of harmonic univalent functions. Such as, ([6], [7], [9], [11]).

A variable $x$ is said to (p,q)-Poisson Distribution if it takes the values $0,1,2,3, \ldots$ with probabilities $e_{p, q}^{-r}, \frac{r}{[1]_{p, q} !} e_{p, q}^{-r}, \frac{r^{2}}{[2]_{p, q} !} e_{p, q}^{-r}$, $\ldots$, respectively, where $r$ a parameter and

$$
\begin{aligned}
& e_{p, q}^{x}=1+\frac{x}{[1]_{p, q} !}+\frac{x^{2}}{[2]_{p, q} !}+\cdots+\frac{x^{k}}{[k]_{p, q} !}+\cdots \\
& =\sum_{k=0}^{\infty} \frac{x^{k}}{[k]_{p, q} !}
\end{aligned}
$$

is $(\mathrm{p}, \mathrm{q})$-analogue of the exponential function $e^{x}$ and

$$
[k]_{p, q} !=[1]_{p, q}[2]_{p, q} \ldots[k]_{p, q}
$$

is $(\mathrm{p}, \mathrm{q})$-analogue of the factorial function $k !=1.2 .3 \ldots k$. Thus, for $(p, q)$-Poisson Distribution, we have 


$$
P_{p, q}^{r}(x=k)=\frac{r^{k}}{[k]_{p, q} !} e_{p, q}^{-r}, \quad k=1,2,3, \ldots
$$

Now, we introduce a power series whose coefficients are probabilities of the $(\mathrm{p}, \mathrm{q})$-Poisson Distribution, that is

$$
P_{p, q}^{r}(z)=z+\sum_{k=2}^{\infty} \frac{r^{k-1} e_{p, q}^{-r}}{[k-1]_{p, q} !} z^{k} \quad(z \in U) .
$$

Note that, by using ratio test we conclude that the radius of convergence of the above power series is infinity. Now, for $r, s>0$ and $0<p, q<1$, we introduce the analytic functions

$$
\begin{aligned}
& P_{p, q}^{r}(z)=z+\sum_{k=2}^{\infty} \frac{r^{k-1} e_{p, q}^{-r}}{[k-1]_{p, q} !} z^{k} \quad \text { and } P_{p, q}^{s}(z) \\
& =z+\sum_{k=2}^{\infty} \frac{s^{k-1} e_{p, q}^{-s}}{[k-1]_{p, q} !} z^{k} .
\end{aligned}
$$

Let us define harmonic functions $P_{p, q}^{r, s}$ and $T P_{p, q}^{r, s}$ as

$$
\begin{aligned}
& P_{p, q}^{r, s}(z)=P_{p, q}^{r}(z)+\overline{P_{p, q}^{s}(z)-z} \text { and } T P_{p, q}^{r, s} \\
= & 2 z-P_{p, q}^{r}(z)+\overline{P_{p, q}^{s}(z)-z .} \text { (9) }
\end{aligned}
$$

It is clear that $P_{p, q}^{r, s} \in S H_{p, q}^{0}$ and $T P_{p, q}^{r, s} \in T$.

In this study, we define two functions $P_{p, q}^{r, s}$ and $T P_{p, q}^{r, s}$ by (p,q)-Poission Distribution and we aim to find the conditions for these functions to belong to the class of $(p, q)$-harmonic functions.

To demonstrate our theorem we will use the following lemma.

Lemma 1. [1] Let $f=h+\bar{g}$ be given by (1). If for some $\alpha(0 \leq \alpha<1)$ and the inequality

$$
\sum_{\substack{k=2 \\ \leq 1-\alpha}}^{\infty}\left([k]_{p, q}-\alpha\right)\left|a_{k}\right|+\sum_{\substack{k=1 \\(10)}}^{\infty}\left([k]_{p, q}+\alpha\right)\left|b_{k}\right|
$$

is hold, then $f$ is harmonic, sense-preserving, univalent in $U$ and $f \in S H_{p, q}^{*}(\alpha)$.

Remark 2. [1] Let $f=h+\bar{g}$ be given by (6). Then $f \in$ $\operatorname{TSH}_{p, q}^{*}(\alpha)$ if and only if the coefficient condition (10) is satisfied.

\section{Main Results}

Theorem 3. If $r, s>0,0<p, q<1,0 \leq \alpha<1$ and the inequality

$$
\begin{aligned}
& (p+q)(r+s)+e_{p, q}^{-r(1-p)}+e_{p, q}^{-r(1-q)}+e_{p, q}^{-s(1-p)} \\
& \quad+e_{p, q}^{-s(1-q)} \\
& \quad \leq 2(1-\alpha)\left(1+e_{p, q}^{-r}\right)+2(1+\alpha) e_{p, q}^{-s}
\end{aligned}
$$

is satisfied then $P_{p, q}^{r, s} \in S H_{p, q}^{*, 0}(\alpha)$.

Proof. Let $\mathrm{r}, \mathrm{s}>0,0<\mathrm{p}, \mathrm{q}<1,0 \leq \alpha<1$. Referring Lemma 1 , It is sufficient to show that the inequality

$$
\sum_{\mathrm{k}=2}^{\infty}\left\{\left([\mathrm{k}]_{\mathrm{p}, \mathrm{q}}-\alpha\right) \frac{\mathrm{r}^{\mathrm{k}-1} \mathrm{e}_{\mathrm{p}, \mathrm{q}}^{-\mathrm{r}}}{[\mathrm{k}-1]_{\mathrm{p}, \mathrm{q}} !}+\left([\mathrm{k}]_{\mathrm{p}, \mathrm{q}}+\alpha\right) \frac{\mathrm{s}^{\mathrm{k}-1} \mathrm{e}_{\mathrm{p}, \mathrm{q}}^{-\mathrm{s}}}{[\mathrm{k}-1]_{\mathrm{p}, \mathrm{q}} !}\right\}
$$

$$
\leq 1-\alpha
$$

is satisfied to show that the function $\mathrm{P}_{\mathrm{p}, \mathrm{q}}^{\mathrm{r}, \mathrm{s}}(\mathrm{z})=\mathrm{P}_{\mathrm{p}, \mathrm{q}}^{\mathrm{r}}(\mathrm{z})+$ $\overline{\mathrm{P}_{\mathrm{p}, \mathrm{q}}^{\mathrm{s}}(\mathrm{z})-\mathrm{z}}$ belongs to the class $\mathrm{SH}_{\mathrm{p}, \mathrm{q}}^{*, 0}(\alpha)$ where $\mathrm{P}_{\mathrm{p}, \mathrm{q}}^{\mathrm{r}}$ and $\mathrm{P}_{\mathrm{p}, \mathrm{q}}^{\mathrm{s}}$ are given by (8). Then, using the inequality (7), we obtain

$$
\begin{aligned}
& \sum_{k=2}^{\infty}\left\{\left([k]_{p, q}-\alpha\right) \frac{r^{k-1} e_{p, q}^{-r}}{[k-1]_{p, q} !}+\left([k]_{p, q}+\alpha\right) \frac{s^{k-1} e_{p, q}^{-s}}{[k-1]_{p, q} !}\right\} \\
& =\sum_{k=2}^{\infty}\left\{\left(\frac{p+q}{2}[k-1]_{p, q}+\frac{p^{k-1}+q^{k-1}}{2}\right.\right. \\
& -\alpha) \frac{r^{k-1} e_{p, q}^{-r}}{[k-1]_{p, q} !} \\
& +\left(\frac{p+q}{2}[k-1]_{p, q}+\frac{p^{k-1}+q^{k-1}}{2}\right. \\
& \left.+\alpha) \frac{s^{k-1} e_{p, q}^{-s}}{[k-1]_{p, q} !}\right\} \\
& =\frac{p+q}{2} \sum_{k=2}^{\infty} \frac{r^{k-1} e_{p, q}^{-r}}{[k-2]_{p, q} !} \\
& +\sum_{k=2}^{\infty}\left(\frac{p^{k-1}+q^{k-1}}{2}-\alpha\right) \frac{r^{k-1} e_{p, q}^{-r}}{[k-1]_{p, q} !} \\
& +\frac{p+q}{2} \sum_{k=2}^{\infty} \frac{s^{k-1} e_{p, q}^{-s}}{[k-2]_{p, q} !}+\sum_{k=2}^{\infty}\left(\frac{p^{k-1}+q^{k-1}}{2}+\alpha\right) \frac{s^{k-1} e_{p, q}^{-s}}{[k-1]_{p, q} !} \\
& =\frac{(p+q) r e_{p, q}^{-r}}{2} \sum_{k=0}^{\infty} \frac{r^{k}}{[k]_{p, q} !}+\frac{1}{2} e_{p, q}^{-r} \sum_{k=1}^{\infty} \frac{(p r)^{k}}{[k]_{p, q} !} \\
& +\frac{1}{2} e_{p, q}^{-r} \sum_{k=1}^{\infty} \frac{(q r)^{k}}{[k]_{p, q} !}-\alpha e_{p, q}^{-r} \sum_{k=1}^{\infty} \frac{r^{k}}{[k]_{p, q} !} \\
& +\frac{(p+q) s e_{p, q}^{-s}}{2} \sum_{k=0}^{\infty} \frac{s^{k}}{[k]_{p, q} !}+\frac{1}{2} e_{p, q}^{-s} \sum_{k=1}^{\infty} \frac{(p s)^{k}}{[k]_{p, q} !} \\
& +\frac{1}{2} e_{p, q}^{-s} \sum_{k=1}^{\infty} \frac{(q s)^{k}}{[k]_{p, q} !} \\
& +\alpha e_{p, q}^{-s} \sum_{k=1}^{\infty} \frac{s^{k}}{[k]_{p, q} !} \\
& =\frac{p+q}{2} r+\frac{1}{2} e_{p, q}^{-r}\left(e_{p, q}^{r p}-1\right)+\frac{1}{2} e_{p, q}^{-r}\left(e_{p, q}^{r q}-1\right) \\
& -\alpha e_{p, q}^{-r}\left(e_{p, q}^{r}-1\right)+\frac{p+q}{2} s \\
& +\frac{1}{2} e_{p, q}^{-s}\left(e_{p, q}^{s p}-1\right)+\frac{1}{2} e_{p, q}^{-s}\left(e_{p, q}^{s q}-1\right) \\
& +\alpha e_{p, q}^{-s}\left(e_{p, q}^{s}-1\right) \text {. }
\end{aligned}
$$

Therefore, inequality (13) holds true if

$$
\begin{gathered}
\frac{(p+q)(r+s)}{2}+\frac{1}{2} e_{p, q}^{-r(1-p)}+\frac{1}{2} e_{p, q}^{-r(1-q)}+\frac{1}{2} e_{p, q}^{-s(1-p)} \\
+\frac{1}{2} e_{p, q}^{-s(1-q)} \\
-(1-\alpha) e_{p, q}^{-r}-(1+\alpha) e_{p, q}^{-s} \leq 1-\alpha
\end{gathered}
$$

which is equivalent to (12). Thus, the proof of Theorem 3. 
Corollary 4. If $r, s>0,0<p, q<1,0 \leq \alpha<1$, then the function $T P_{p, q}^{r, s}$ defined by (9) belongs to the class $\operatorname{TSH}_{p, q}^{*, 0}(\alpha)$ if and only if satisfied inequality (12).

\section{Conclusions and Recommendations}

The novelty of the above results consists in the fact that using some recent results we found sufficient conditions such that the function $P_{p, q}^{r, s}$ defined by (9) belongs to the class $S H_{p, q}^{*, 0}(\alpha)$.

Moreover, for appropriate choices of the parameters we found a few interesting special cases of the above main results.

Finally, new subclass analysis can be done using this method in the future

\section{References}

[1] Alsobah, A., Darus, M. (2019). On Subclasses of Harmonic Univalent Functions Defined by Jackson (p,q) Derivative, Journal of Analysis, 10(3), 123-130.

[2] Chakrabarti, R., Jagannathan, R. (1991). A (p, q)-oscillator realization of two- parameter quantum algebras, J. Phys. A 24(13), L711.L718.

[3] Clunie, J., Sheil-Small, T. (1984). Harmonic univalent functions, Ann. Acad. Sci. Fenn. Ser. A I Math. 9, 3-25.

[4] Ismail, M. E. H., Merkes, E., Steyr, D. (1990). A generalization of starlike functions, Complex Variables Theory Appl. 14(1), 77-84.

[5] Jackson, F. H. (1908). On q-functions and a certain difference operator, Transactions of the Royal Society of Edinburgh, Vol:46, 253-281.

[6] Jahangiri, J.M. (2018). Harmonic univalent functions defined by q- calculus operators, Inter.J. Math. Anal. Appl. $5(2), 39.43$.

[7] Jahangiri, J.M. (1999). Harmonic functions starlike in the unit disk, J. Math. Anal. Appl. 235, 470-477.

[8] Mustafa, J.M. Nezir, V. (2021). Analytic functions expressed with q-Poisson distribution series, Turkish Journal of Science, 6(1), 24-30.

[9] Nazeer, W., Mehmood, Q., Kang, S.M., Haq, A. U. (2019). An application of Binomial distribution series on certain analytic functions, Journal of Computational Analysis and Applications, 26, 11-17.

[10] Porwal, S., Srivastava, D. (2017). Harmonic starlikeness and convexity of integral operators generated by Poisson distribution series, Math. Morav. 21(1) 51-60.

[9] Silverman, H., Silvia, E.M. (1999). Subclasses of harmonic univalent functions, New Zeland J. Math. 28 275-284.

[10]Sahai, V., Yadav, S. (2007). Representations of two parameter quantum algebras and $\mathrm{p}, \mathrm{q}$-special functions, J. Math. Anal. Appl. 335, 268.279.

[11]Seoudy, T. M., Aouf, M.K. (2016). Coefficient estimates of new classes of q-starlike and q-convex functions of complex order, J. Math. Inequal. 10(1), 135-145. 